\title{
DESKRIPSI, KEANEKARAGAMAN JENIS DAN KELIMPAHAN KEPITING (BRACYURA DECAPODA) DI PERAIRAN BAHOWO KELURAHAN TONGKEINA KECAMATAN BUNAKEN KOTA MANADO
}

\author{
Sophian Ch Michael*, Erly Y. Kaligis, Joice R. T. S. L. Rimper \\ Program Studi IImu Kelautan FPIK Unsrat Manado \\ *Email : pianwarongan@gmail.com
}

\begin{abstract}
The waters of Bahowo are located in North Sulawesi Province, Tongkeina Village, District of Bunaken, which is one of the mangrove ecotourism destinations with a high density of mangrove ecosystems. Crab sampling activities were carried out by the cruise method with a distance of 500 meters at each observation station. The steps in this research are; collecting specimens, identifying and taking pictures. After that, the transect line is used to determine density and species diversity. then determined 3 different stations with a distance of $150 \mathrm{~m}$ each. Each transect station is $10 \times 10$ meters consisting of 100 quadrants with a distance between 1 meter quadrants. Determination of the quadrant where sampling is done randomly at each station Results of research in the waters of Bahowo, obtained the number of crabs that is 125 individuals. From the results of identification of crabs that have been obtained there are 15 species, namely: Scylla serrate, S. olivacea, S. tranquabarica, S. paramamosain, Thalamita crenata, Thalamita danae, Portunus pelagicus, Portunus trituberculatus, Metopograpsus thukuhar, Cardisoma carnivex, Myalamita crenata, Thalamita danae, Portunus pelagicus, Portunus trituberculatus, Metopograpsus thukuhar, Cardisoma carnivex, Myomenita eumolpe, Austruca annulipes, Paraleptuca chlorophthalmus, Galasimus vomeris. Galasimus vomeris type crabs showed the highest abundance of 2.8 ind / m2, while the lowest in Cylla olivacea and S. tranquabarica, which was 0.1 ind / m2.
\end{abstract}

Keywords: Species diversity, abundance, Brachyura

\begin{abstract}
Abstrak
Perairan Bahowo terletak di Provinsi Sulawesi Utara Kelurahan Tongkeina Kecamatan Bunaken yang menjadi salah satu tempat destinasi ekowisata mangrove dengan kepadatan ekosistem mangrove yang cukup tinggi..Lokasi kelurahan ini terletak di sebelah utara Kota Manado yang termasuk wilayah konservasi mangrove. Kegiatan pengambilan sampel kepiting dilakukan dengan metode jelajah (cruise method) dengan jarak 500 meter pada masing-masing stasiun pengamatan. langkah-langkah dalam penelitian ini adalah mengumpulkan spesimen, mengidentifikasi dan mengambil gambar Setelah itu, garis transek digunakan untuk menentukan kepadatan dan keanekaragaman jenis. kemudian ditentukan 3 stasion berbeda dengan jarak masing-masing $150 \mathrm{~m}$. Masing-masing station transek berupa $10 \times 10$ meter yang terdiri 100 kuadran dengan jarak antara kuadran 1 meter. Penentuan kuadran tempat pengambilan sampel dilakukan secara acak pada masing-masing stasion Hasil penelitian di perairan Bahowo, didapatkan jumlah kepiting yaitu 125 individu. Dari hasil identifikasi kepiting yang telah dilakukan didapat ada 15 spesies yaitu: Scylla serrate, S. olivacea, S. tranquabarica, S. paramamosain, Thalamita crenata, Thalamita danae, Portunus pelagicus, Portunus trituberculatus, Metopograpsus thukuhar, Cardisoma carnivex, Myomenippe spp, Perisesarma eumolpe, Austruca annulipes, Paraleptuca chlorophthalmus, Galasimus vomeris. Kepiting jenis Galasimus vomeris menunjukan kelimpahan tertinggi yaitu 2,8 ind $/ \mathrm{m}^{2}$, sedangkan yang terendah pada Scylla olivacea dan S. tranquabarica, yaitu $0,1 \mathrm{ind} / \mathrm{m}^{2}$.
\end{abstract}

Kata kunci :Keanekaragaman jenis, kelimpahan, Brachyura 


\section{PENDAHULUAN}

Krustasea adalah bagian penting dari fauna bentik dan secara khusus adalah infra ordo brachyura. Kepiting brachyura mencakup sekitar 700 genera dan sekitar 5000 hingga 10.000 spesies sehubungan kelimpahan biomassa dan struktur komunitasnya ( $\mathrm{Ng}$ et al, 2008). Dalam ekosistem mangrove, kepiting merupakan kelompok hewan utama berperan secara ekologi dalam struktur dan fungsi mangrove. Jenis krustasea ini merupakan penghubung utama rantai makanan antara detritus dengan konsumen tingkat tropik lebih tinggi (Lee, 1999.; Macintosh, 1988)

Kepiting adalah binatang berkaki sepuluh (decapoda) yang biasanya mempunyai ekor yang sangat pendek (bahasa Yunani: brachy = pendek, ura = ekor), atau yang perutnya sama sekali tersembunyi di bawah thorax yang berkembang dengan baik. Kepiting brachyura pada umumnya memiliki 4 pasang kaki gerak, sedangkan jenis kepiting anomura (kepiting semu) memiliki 3 pasang kaki gerak. Tubuh kepiting umumnya ditutpi dengan exoskeleton (kerangka luar) yang sangat keras, dan dipersenjatai dengan sepasang capit. Kepiting hidup di air laut, air tawar dan darat dengan ukuran yang beraneka ragam (Anonim, 2007).

Sejak tahun 1980-an salah satu genus yaitu kepiting bakau telah menjadi komoditas perikanan penting, mempunyai nilai ekonomis penting, dan memiliki harga yang tinggi baik di pasar dalam negeri maupun luar negeri, antara lain di Asia (seperti Singapura, Thailand, Taiwan, Hongkong dan China) maupun di Amerika dan Eropa (Rusdi dan Hanafi, 2009).

Perairan Bahowo terletak di Provinsi Sulawesi Utara Kelurahan Tongkeina Kecamatan Bunaken yang menjadi salah satu tempat destinasi ekowisata mangrove dengan kepadatan ekosistem mangrove yang cukup tinggi (Tuwongkesong, 2018).Lokasi kelurahan ini terletak di sebelah utara Kota Manado yang termasuk wilayah konservasi mangrove. Beberapa kajian tentang struktur komunitas mangrove telah dilakukan dikawasan ini.

\section{METODE PENELITIAN}

\section{Pengambilan Sampel Kepiting}

pada $\begin{array}{cc}\text { Kegiatan penlitian dilaksanakan } \\ \text { perairan }\end{array}$ Tongkeina, Kecamatan Bunaken Kota Manado, Provinsi Sulawesi Utara. Penelitian ini dilaksanakan pada bulan agustus sampai September 2019. Metode yang digunakan adalah metode jelajah (cruise method) dengan membuat lintasan sepanjang $500 \mathrm{~m}$. Lokasi pengambilan data terdiri 3 tempat (stasion) berbeda yang berjarak $300 \mathrm{~m}$ antar stasion, yaitu mencakup bagian dengan habitat lamun, bakau maupun pasir yang merupakan stasion pengamatan. Pengambilan sampel kepiting dilakukan pada masing-masing stasiun dengan diberi tanda berupa kayu yang ditancapkan di substrat agar mempermudah proses kerja lapangan.Untuk memudahkan dalam pengambilan dan pengamatan sampel maka penelitian dilakukan ketika perairan memasuki surut terendah. Untuk menentukan kepadatan dan keanekaragaman jenis maka dilakukan dengan metode transek. Untuk itu dibuat 3 stasion berbeda dengan jarak masingmasing stasion sepanjang $150 \mathrm{~m}$. Pada masing-masing stasion dibuattransek berukuran $10 \times 10$ meter yang terdiri 100 kuadran dengam jarak antara kuadran 1 meter. Penentuan kuadran tempat pengambilan sampel secara acak pada masing-masing stasion (Gambar 1). Pengamatan jenis dan jumlah kepiting dilakukan kemudian pada 5 kuadran di setiap stasion dengan menghitung jumlah setiap jenis kepiting yang ada dalam kuadran. Untuk melengkapi data di lapangan diambil juga data pendukung kualitas air, seperti: suhu, $\mathrm{pH}$, dan salinitas pada masingmasing stasiun. 


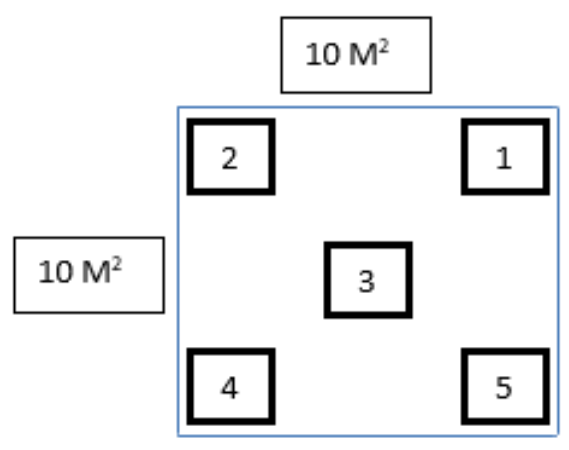

Gambar 1. Ilustrasi penentuan garis transek

\section{Analisis Data}

Identifikasi spesies kepiting (Bracyura) menggunakan buku dari Keenan (2011), FAO (2013), WoRMS (2019';) dan WWF (2015) tentang identifikasi jenis-jenis kepitng. Karakteristik morfologi yang diamati yaitu ukuran panjang tubuh, warna tubuh, dan kelengkapan organ tubuhnya. Pengamatan sampel yang diperoleh berpatokan pada referensi yang digunakan. Data hasil identifikasi akan ditampilkan secara deskriptif demikian juga hasil kualitas air ditampilkan dalam bentuk table.

Rumus pengukuran kelimpahan dalam penelitian ini menggunakan cara (Krebs, 1989) dalam (soegianto, 1994), yaitu

Dimana :

$$
N=\frac{\sum n i}{A}
$$

$\mathrm{N}=$ Kelimpahan kepiting (ind $/ \mathrm{m}^{2}$ )

$\sum n i=$ Jumlah total individu untuk spesies $\mathrm{i}$ (individu)

A = Luas total daerah yang di sampling
Dalam mencari keanekargaman kepitng digunakan rumus indeks Shanonwiener (1949) dalam Ludwig (1984), sebagai berikut :

$$
H^{\prime}=-\sum \frac{n i}{N} \ln \frac{n i}{N}
$$

$$
\begin{array}{ll}
\text { Keterangan } \\
\mathrm{H}^{\prime} \quad \text { : Indek keanekaragaman Shanon } \\
& \text { Wiener } \\
\mathrm{ni} & \text { : Jumlah tiap jenis } \\
\mathrm{N} & \text { : Jumlah total }
\end{array}
$$

Kriteria tingkat keanekaragaman

$$
\begin{array}{ll}
\mathrm{H}^{\prime}<1 & =\text { keanekaragaman rendah } \\
1<\mathrm{H}^{\prime}<3,3 & =\text { keanekaragaman sedang } \\
\mathrm{H}^{\prime}>3,3 & =\text { keanekaragaman tinggi }
\end{array}
$$

\section{HASIL DAN PEMBAHASAN}

\section{Jenis Kepiting}

Berdasarkan hasil identifikasi yang dilakukan pada 3 station pengamatan di Perairam Bahowo Kelurahan Tongkeina Kecamatan Bunaken Kotamadya Manado, didapatkan 15 spesies yang terbagi atas beberapa famili yaitu: Ocypodidae (Austruca annulipes ,Paraleptuca clorophthalmus, Galasimus vomeris), Portunidae (Portunus pelagicus, Portunus trituberculatus, Scylla serrata, Scylla olivacea, Scylla transquabarica, Scylla paramamosain, Thalamita crenata, Thalamita danae), Grapsidae (Metopograpsus thukuhar), Gecarcinidae (Cardisoma carnivex), Menippidae (Myomenippe spp), Sesarmidae (Perisesarma eumolpe. 
Tabel 1.Jumlah kepiting yang ditemukan di perairan Bahowo

\begin{tabular}{|c|c|c|c|c|c|}
\hline \multirow[t]{2}{*}{ No } & \multirow{2}{*}{ Spesies } & \multicolumn{3}{|c|}{ Stasiun } & \multirow{2}{*}{ Jumlah total (ind) } \\
\hline & & 1 & 2 & 3 & \\
\hline 1. & S. serrata & 0 & 2 & 0 & 2 \\
\hline 2. & S. olivacea & 0 & 1 & 0 & 1 \\
\hline 3. & S. tranquabarica & 0 & 1 & 0 & 1 \\
\hline 4. & S. paramamosain & 0 & 2 & 0 & 2 \\
\hline 5. & P. pelagicus & 0 & 0 & 2 & 2 \\
\hline 6. & P. trituberculatus & 0 & 0 & 2 & 2 \\
\hline 7. & T. crenata & 0 & 1 & 3 & 4 \\
\hline 8. & T. danae & 0 & 2 & 4 & 6 \\
\hline 9. & P. eumolpe & 0 & 10 & 0 & 10 \\
\hline 10. & Myomenippe spp & 0 & 8 & 0 & 8 \\
\hline 11 & C. carnivex & 0 & 9 & 0 & 9 \\
\hline 12 & M. thukuhar & 0 & 12 & 0 & 12 \\
\hline 13 & A. annlipes & 20 & 2 & 0 & 22 \\
\hline 14 & P. clorophthalmus & 15 & 1 & 0 & 16 \\
\hline 15 & G. vomeris & 25 & 3 & 0 & 28 \\
\hline & $\sum$ & 60 & 54 & 11 & 125 \\
\hline
\end{tabular}

Dari 15 spesies kepiting hasil tangkapan diperairan Bahowo yang didapatkan dari 3 station, Galasimus vomeris merupakan spesies yang paling banyak didapatkan yaitu 28 ekor, diikuti spesies Austruca annulipes yaitu 22 ekor dan paling sedikit spesies pada Scylla olivacea dan
Scylla tranquabarica yaitu 1 ekor masing masing. Secara keseluruhan kepiting terbanyak pada station 1 yaitu 60 ekor dan station 2 yaitu 54 ekor dan yang terakhir station 3 dengan jumlah 11 ekor.

\section{Kelimpahan Kepiting}

Tabel 2 Kelimpahan kepiting

\begin{tabular}{|c|l|c|c|c|}
\hline \multirow{2}{*}{ No } & \multirow{2}{*}{ Spesies } & \multicolumn{3}{|c|}{ Kelimpahan ind $/ \mathrm{m}^{2}$} \\
\cline { 3 - 5 } & & 1 & 2 & 3 \\
\hline 1. & S. serrata & - & 0,2 & - \\
\hline 2. & S. olivacea & - & 0,1 & - \\
\hline 3. & S. tranquabarica & - & 0,1 & - \\
\hline 4. & $\begin{array}{l}\text { S. } \\
\text { paramamosain }\end{array}$ & - & 0,2 & - \\
\hline 5. & P. pelagicus & - & - & 0,2 \\
\hline 6. & P. trituberculatus & - & - & 0,2 \\
\hline 7. & T. crenata & - & 0,1 & 0,3 \\
\hline 8. & T. danae & - & 0,2 & 0,4 \\
\hline 9. & P. eumolpe & - & 1 & - \\
\hline
\end{tabular}




\begin{tabular}{|c|l|c|c|c|}
\hline 10. & $\begin{array}{l}\text { Myomenippe } \\
\text { spp }\end{array}$ & - & 0,8 & - \\
\hline 11 & C. carnivex & - & 0,9 & - \\
\hline 12 & M. thukuhar & - & 1,2 & - \\
\hline 13 & A. annlipes & 1,6 & 0,2 & - \\
\hline 14 & $\begin{array}{l}\text { P. } \\
\text { clorophthalmus }\end{array}$ & 2,2 & 0,1 & - \\
\hline 15 & G. vomeris & 2,8 & 0,3 & - \\
\hline \multicolumn{2}{|c}{} & 6,6 & 6,6 & 1,1 \\
\hline
\end{tabular}

Kepiting Ocypodidae adalah salah satu kepiting yang memiliki habitat di daerah pasang surut (Murniati, 2009) Hasil kelimpahan kepiting pada station 1 menunjukan bahwa dari 3 spesies kepiting yang ditemukan jenis Gelasimus vomeris menunjukan kelimpahan tertinggi yaitu 2,8 ind $/ \mathrm{m}^{2}$, sedangkan kelimpahan terendah adalah Paraleptuca clorophthalmus yaitu 1,6 ind $/ \mathrm{m}^{2}$.

Hasil kelimpahan kepiting pada station 2 menunjukan bahwa dari 13 spesies kepiting yang ditemukan, jenis Methopograpsus thukuhar menunjukan kelimpahan tertinggi yaitu 2,1 ind $/ \mathrm{m}^{2}$, sedangkan kelimpahan terendah didapatkan 4 spesies yaitu Austruca annulipes, Paraleptuca clorophthalmus, Scylla olivacea dan Scylla tranqubarica dengan masingmasingmemiliki angka kelimpahan taitu 0,1 ind $/ \mathrm{m}^{2}$.

Indeks Keanekaragaman Jenis Kepiting

Tabel 3. Indeks keanekaragaman jenis kepiting

\begin{tabular}{|c|c|c|c|c|}
\hline No & Spesies & $\frac{n i}{\mathrm{~N}}$ & $\ln \frac{n i}{N}$ & $-\left(\frac{n i}{N} \ln \frac{\mathrm{ni}}{N}\right)$ \\
\hline 1 & S. serrata & 0.016 & -4.135 & 0.06 \\
\hline 2 & S. olivacea & 0.008 & -4.828 & 0.03 \\
\hline 3 & S. tranquabarica & 0.008 & -4.828 & 0.03 \\
\hline 4 & S. paramamosain & 0.016 & -4.135 & 0.06 \\
\hline 5 & P. pelagicus & 0.016 & -4.135 & 0.06 \\
\hline 6 & P. trituberculatus & 0.016 & -4.135 & 0.06 \\
\hline 7 & T. crenata & 0.032 & -3.442 & 0.11 \\
\hline 8 & T. danae & 0.048 & -3.036 & 0.14 \\
\hline 9 & P. eumolpe & 0.08 & -2.525 & 0.20 \\
\hline 10 & Myomenippe spp & 0.064 & -2.748 & 0.17 \\
\hline 11 & C. carnivex & 0.072 & -2.631 & 0.18 \\
\hline 12 & M. thukuhar & 0.096 & -2.343 & 0.22 \\
\hline 13 & U. annlipes & 0.176 & -1.737 & 0.30 \\
\hline 14 & U. clorophthalmus & 0.128 & -2.055 & 0.26 \\
\hline 15 & U. vomeris & 0.224 & -1.496 & 0.33 \\
\hline \multicolumn{4}{|c|}{$\bar{\Sigma} H^{\prime}$} & 2.3 \\
\hline
\end{tabular}

Hasil analisis data indeks keanekaragaman jenis kepiting yaitu 2,3 dalam kriteria yang mendekati keanekaraman jenis sedang, dimana keanekaragaman jenis sedang adalah 3,3. Keanekaragaman jenis kepiting dalam suatu perairan menunjukan kondisi lingkungan perairan tersebut, adanya jenis-jenis kepiting 
yang lebih beragam mengindikasikan bahwa kondisi perairan tersebut mendukung bagi kelangsungan hidup jenis kepiting Sembiring (2008).

\section{Kualitas Lingkungan Perairan}

Selama penelitian dilakukan pengamatan kualitas lingkungan perairan yang meliputi kualitas air (suhu, pH, salinitas). Hasil pengukuran secara keseluruhan pada 3 station pengamatan disajikan pada table 4 .

Tabel 4. Hasil pengukuran parameter lingkungan di tiap station di Perairan Bahowo.

\begin{tabular}{|c|c|c|c|c|c|}
\hline \multirow{2}{*}{ No. } & \multirow{2}{*}{ Parameter } & \multirow{2}{*}{ Satuan } & \multicolumn{3}{|c|}{ Stasiun } \\
\cline { 4 - 6 } & & & $\mathrm{I}$ & $\mathrm{II}$ & III \\
\hline 1. & Suhu & ${ }^{\circ} \mathrm{C}$ & $27-29$ & $26-28$ & $27-30$ \\
\hline 2. & $\mathrm{pH}$ & - & $6,8-7,5$ & $7,2-7,8$ & $7,4-8,0$ \\
\hline 3. & Salinitas & Ppt & $27-29$ & $29-30$ & $31-32$ \\
\hline
\end{tabular}

Hasil pengukuran suhu pada Stasiun I nilainya yaitu $27-29^{\circ} \mathrm{C}$, Stasiun II yaitu 26 $28{ }^{\circ} \mathrm{C}$ dan Stasiun III yaitu 27-30 ${ }^{\circ} \mathrm{C}$.Pengukuran suhu dilakukan saat pengamatan dan sampling yaitu, siang dan malam hari.Kisaran suhu selamapenelitian pada masing-masing stasiun merupakan kisaran normal.Menurut (KEPMEN-LH, 2004) suhu air yang baik untuk krustasea adalah $28-33^{\circ} \mathrm{C} /$

\section{PEMBAHASAN}

Hasil penelitian di perairan Bahowo, Kecamatan Bunakaen didapatkan jumlah kepiting yaitu 125 individu. Dari hasil identifikasi kepiting yang telah dilakukan didapat ada 15 yaitu: Scylla serrate, $S$. olivacea, $S$. tranquabarica, $S$. paramamosain, Thalamita crenata, Thalamita danae, Portunus pelagicus, Portunus trituberculatus, Metopograpsus thukuhar, Cardisoma carnivex, Myomenippe spp, Perisesarma eumolpe, Austruca annulipes, Paraleptucachlorophthalmus, Galasimus Vo meris.
Hasil pengukuran $\mathrm{pH}$ pada ketiga stasiun penelitian, didapatkan nilai Stasiun I sampai III yakni6,8-7,5; 7,2-7,8 dan 7,4-8,0. Dari nilai $\mathrm{pH}$ tersebut tergolongcukupbaik bagi kehidupan udang dan kepiting, halinisesuaidenganpernyataanSiahainenia (2008) yang mengatakanbahwa $\mathrm{pH}$ yang baik untuk udang dan kepiting adalah $\mathrm{pH}$ 6,5-9.

Kepiting jenis Galasimus vomeris menunjukan kelimpahan tertinggi yaitu 2,8 ind $/ \mathrm{m}^{2}$, sedangkan yang terendah pada Scylla olivacea dan S. tranquabarica, yaitu $0,1 \mathrm{ind} / \mathrm{m}^{2}$.Kelimpahan kepiting dalam penelitian ini lebih tinggi dibandingkan laporan Marbun (2019) yang mengkaji kelimpahan kepiting Austruca annulipes menunjukan kelimpahan tertinggi 0,126 ind $/ \mathrm{m}^{2}$, sedangkan yang terendah adalah P.trituberculatus, yaitu 0,003 ind $/ \mathrm{m}^{2}$. Menurut (Moosa, 2014) faktor yang dapat mempengaruhi kelimpahan spesies adalah kualitas lingkungan perairan yang mendukung kehidupan dari jenis kepiting 


\section{KESIMPULAN DAN SARAN}

\section{Kesimpulan}

Indeks keanekaragaman jenis kepiting yaitu 2,3 dalam kriteria yang mendekati keanekaraman jenis sedang, dimana keanekaragaman jenis sedang adalah 3,3. Sedangkan Hasil kelimpahan kepiting menunjukan bahwa dari 15 spesies kepiting yang ditemukan jenis Galasimus vomeris menunjukan kelimpahan tertinggi yaitu 2,8 ind $/ \mathrm{m}^{2}$, sedangkan kepadatan terendah adalah Scylla olivacea dan Scylla tranquabarica yaitu $0,1 \mathrm{ind} / \mathrm{m}^{2}$

Kepiting yang diperoleh dari Perairan Bahowo Kecamatan Bunaken, Kotamadya Manado berjumlah 15 spesies yaitu Scylla serrate, $S$. olivacea, $S$. tranquabarica, $S$. paramamosain, Thalamita crenata, Thalamita danae, Portunus pelagicus, Portunus trituberculatus, Metopograpsus thukuhar, Cardisoma carnivex, Myomenippe spp, Perisesarma eumolpe, Austruca annulipes,

Paraleptucachlorophthalmus, Galasimus Vo meris.Jumlah total kepiting yang ditemukan 125 ekor. Parameter lingkungandi tiap stasiunberada pada kondisi yang layak bagi kehidupan kepiting.

\section{Saran}

Perlu dilakukan penelitian lanjutan tentang jenis krustasea lainnya serta keanekaragaman jenis di perairan Bahowo Kecamatan Bunaken, Kota Manado.

\section{DAFTAR PUSTAKA}

Anonim . 2007. Pengamatan Aspek Biologi Rajungan Dalam Menunjang Teknik Pembenihan, (Online), http://www.utkampus.net, di akses 23 November 2019).

Lee, S.Y. 1999. The effect of mangrove leaf litter enrichment onmacrobenthic colonization of defaunated sandy substrates. Estuarine, Coastal and Shelf Science, 49:703-712.

Rusdi I., dan A. Hanafi. 2009. Pembesaran Krablet Kepiting Bakau (Scylla Serrata,
Forskal) Secara Morfologis dan Kaitannya dengan Perkembangan Gamet. Skripsi (tidak dipublikasikan) Fakultas Perikanan, IPB.

Tuwongkesong. H. 2018. Kajian Ekologis Ekosistem Mangrove untuk Ekowisata di Bahowo Kota Manado.Majalah Geografi Indonesia. Vol. 32, No.2.

Keenan, C. P., P. J. F. Davie, dan D. L. Mann. 2011. 'A Revision of The Genus Scylla de Haan, 1833 (Crustacea : Dekapoda : Brachyura : Portunidae\}', Raffles Bulletin of Zoology 46 : 217245.

WoRMS (World Register of Marine Species). 2019. Marine Species. [Online]. Tersedia: http://www.marinespecies.org/. Januari 2019].

Soegianto, A. 1994. Ekologi Kuantitatif: Metode Analisis Populasi dan Komunitas. Jakarta: Penerbit Usaha Nasional. $43 \mathrm{hlm}$.

Krebs, C. J. (1989). Ecological Metodology. New York: Harper Collins Publisher.

Sembiring, H. (2008). Keanekaragaman dan Distribusi Udang serta Kaitannya dengan Faktor Fisika Kimia di Perairan Pantai Labu Kabupaten Deli Serdang.Tesis. Medan: Universitas Sumatera Utara.

Keputusan Menteri Negara Lingkungan Hidup No. 51. 2004. Baku Mutu Air Laut Untuk Biota Laut.

Moosa, M.K. dan I. Aswandi. 2014. Udang dan kepiting dariperairanlndonesia. ProyekStudiPotensiSumberdayaAlam Indonesia,

StudiPotensiSumberdayalkan.

LembagaOseanologi Nasional, LIPI, Jakarta: 1-23.

Marbun, J. 2019. Inventarisasi dan Kepadatan Udang dan Kepiting di Perairan Manggrove.Skripsi.FPIKUNSRAT. Manado. Vol 7 No. 2

Siahainenia, L. 2008. Bioekologi Kepiting Bakau (Scylla spp.) di Ekosistem Mangrove Kabupaten Subang Jawa Barat.Disertasi Program Pascasarjana IPB. Bogor. 